\title{
Effects of calcium supplementation on oxidative status and oxidative damage in great tit nestlings inhabiting a metal-polluted area
}

Pablo Sánchez-Virosta ${ }^{1,2 *}$, Silvia Espín ${ }^{1,2}$, Sandra Ruiz ${ }^{1}$, Janina Stauffer ${ }^{1}$, Mirella Kanerva ${ }^{1}$, Antonio J. García-Fernández ${ }^{2}$, Tapio Eeva ${ }^{1}$

${ }^{1}$ Department of Biology, University of Turku, 20014 Turku, Finland.

${ }^{2}$ Area of Toxicology, Department of Socio-Sanitary Sciences, IMIB-Arrixaca, University of Murcia, Campus de Espinardo, 30100 Murcia, Spain.

*Corresponding author: Pablo Sánchez-Virosta. E-mail address: pasanv@utu.fi Telephone: +35823336559 


\section{Abstract}

Calcium has been proposed to diminish metal toxicity by the modulation of the oxidative stress. This study explores the effects of $\mathrm{Ca}$ availability and metal exposure on oxidative stress biomarkers in great tit (Parus major) nestlings. Nests were supplemented with $\mathrm{Ca}$ (Casupplemented group) or not supplemented (Control group) in a metal-polluted and a background zone in SW Finland. Metal concentrations were analyzed from feces. We analyzed antioxidant molecules (tGSH, GSH:GSSG ratio, CAT, GST, GPx, SOD), protein carbonylation and lipid peroxidation in red cells of nestlings. Ca-supplemented and fast-growing nestlings up-regulate CAT activity to cope with ROS generated during intensive growth and metabolism.

SOD and GPx (not statistically significant) were more active in the polluted area, possibly reflecting higher ROS production in nestlings from this zone due to the enhanced metal exposure and worse condition (nestling size and number of fledglings were lower in this area). Antioxidant levels changed over the range of metal concentrations depending on the Ca levels in plasma, suggesting that higher $\mathrm{Ca}$ levels stimulate antioxidants and mitigate the impacts of metals. Ca supplementation may improve nestling traits and reproductive output when antioxidants are up-regulated in a situation of oxidative challenge. Therefore, $\mathrm{Ca}$ should be considered in future studies assessing metal exposure and effects on wild birds.

Keywords: antioxidants, protein carbonylation, lipid peroxidation, calcium availability, metal pollution 


\section{Introduction}

The production of free radicals via oxidative processes is natural in the cellular metabolism of living beings, including birds. The reactive oxygen species (ROS) are unstable and highly reactive by-products of the metabolism of the organism (Finkel and Holbrook, 2000), and they are produced, for example, by increased metabolic activity during the fast growth of embryos and hatchlings (Alonso-Álvarez et al., 2007; Deeming and Pike, 2013; and references therein). However, an integrated antioxidant system protects birds, as other organisms, from oxidative damage (McGraw, 2011). The disequilibrium between the generation of ROS and antioxidants, where the former overcome the physiological defense against free radicals causing oxidative damage to lipids, proteins and DNA, is known as oxidative stress (Halliwell and Gutteridge, 2007).

Some metals, including those that are essential for the normal physiology of cells, such as copper $(\mathrm{Cu})$ and zinc $(\mathrm{Zn})$ and those that are either unnecessary (with no biological function) or needed at very low concentrations, such as $\mathrm{As}, \mathrm{Cd}, \mathrm{Pb}$ or $\mathrm{Hg}$, can alter behavior, development, immune response, reproductive success, and biochemical processes (Burger and Gochfeld, 2000; Flora et al., 2008; García-Fernández et al., 2002; Marettová et al., 2015; Sánchez-Virosta et al., 2015, 2018; Wolfe et al., 1998). The ability of toxic metals to break the antioxidant-ROS balance inducing oxidative stress in birds is one of the mechanisms responsible of their widely reported toxicity (reviewed by Koivula and Eeva, 2010). In the last years, this metal-related oxidative stress has been studied in some avian species (Berglund et al., 2007; Espín et al., 2014a, 2014b; Martínez-Haro et al., 2011; Rainio et al., 2013, 2015).

On the other hand, $\mathrm{Ca}$ is an essential element with a critical physiological role in birds. For successful breeding, small passerines ingest Ca-rich material such as the shells of snails to complement their Ca-deficient regular diet (see for instance Graveland, 1995, 1996). Therefore, Ca-poor environments may pose problems to passerines due to $\mathrm{Ca}$ limitation, such as reduced 
egg size, eggshell thickness, clutch size, number of fledglings or growth rate (reviewed by Reynolds et al., 2004). Moreover, if this is coupled with metal pollution, additional problems may arise. Metal-polluted environments may decrease the stock of Ca-rich food (Eeva et al., 2010), and the absorption, accumulation and effects of metals such as $\mathrm{Cd}$ and $\mathrm{Pb}$ in birds can be increased by this lack in the diet (Dauwe et al., 2006; Scheuhammer, 1996). In addition, As may modify the Ca homeostasis and its function (Florea and Büsselberg, 2008; Florea et al., 2005; Pounds, 1984; Suzuki et al., 2004, 1985). In this regard, some studies have found that the administration of Ca may have a defensive role against As and metal toxicity, and some of them found that $\mathrm{Ca}$ may modulate metal (As)-induced oxidative stress (Abdel-Hameid, 2009; Jamakala and Rani, 2012; Prasanthi et al., 2010; Rai et al., 2012; Srivastava et al., 2010).

The main aim of this study is to investigate the effects of metal exposure and Ca availability on biomarkers of oxidative stress in great tit nestlings inhabiting a metal-polluted zone. To do so, we have studied a set of antioxidant molecules (tGSH, GSH:GSSG ratio, GST, GPx, SOD and CAT; for full names, see Table 1) as well as oxidative damage biomarkers (lipid peroxidation and protein carbonylation, PC) expected to be potential indicators of metal toxicity. Furthermore, we will evaluate if Ca consumption affects the antioxidant status and if it protects against the metal toxicity. Additionally, to assess how nestling development is affected by the antioxidant status, the effects of oxidative damage and antioxidant molecules on nestling size (body mass and the lengths of wing, tarsus and head), growth, fledging success and number of fledglings will be evaluated.

\section{Material and methods}

\section{Experimental set-up, sampling and measurements}

The $\mathrm{Ca}$ experiment was implemented in the proximity of a $\mathrm{Cu}-\mathrm{Ni}$ smelter in Harjavalta, southwestern Finland $\left(61^{\circ} 20^{\prime}\right.$ N, $22^{\circ} 10^{\prime}$ E) during the breeding period of 2014. Due to past and ongoing deposition, metals (mainly $\mathrm{As}, \mathrm{Cd}, \mathrm{Cu}, \mathrm{Ni}$ and $\mathrm{Pb}$ ) are common pollutants in the surroundings of the smelter (Berglund et al., 2012; Rainio et al., 2013). Details on Ca 
availability and metal pollution in the study area are shown in Espín et al. (2016a). The study was conducted on populations of great tit and pied flycatcher (Ficedula hypoleuca; Espín et al., 2017a) using nest boxes (see Lambrechts et al., 2010) located along the pollution gradient. The study area was split into polluted $(0-2 \mathrm{~km}$ from the smelter) and unpolluted $(4.5-11 \mathrm{~km}$ from the smelter) zones. Before the beginning of nest construction, the old nest material was removed and nest boxes were monitored from mid-April to check the nest development and to register laying and hatching dates, clutch and brood sizes and fledgling number. Nests were assigned randomly either to the Ca-supplemented group (hereafter Ca-group) or to the control group when found in an advanced construction phase. In that moment, small modified cylindrical plastic cups containing 5 grams of smashed mussel shells (Versele Laga) were fixed inside the Ca-group nest boxes, whereas in control nests the same cups without shells were placed to control their possible influence on breeding parameters. Feeders were refilled before Ca was finished to provide ad libitum supplementation, and the amount added was recorded. When incubation began and right after hatching (hereafter $\mathrm{d} 0$ ), remaining shells were weighed and replaced. At d14, the last day of sampling, the remaining Ca was removed and weighed. The use of $\mathrm{Ca}$ during laying, incubation and nestling periods was measured, considering any amount added when applicable. Five polluted and 5 unpolluted sites were used in this experiment. In the polluted zone, 14 Ca-supplemented and 17 control nests were set, whereas in the unpolluted zone there were $15 \mathrm{Ca}$-supplemented and 21 control nests.

One egg per clutch was taken to assess how the experiment influenced egg size, eggshell parameters and yolk carotenoid and vitamin concentrations (Espín et al., 2016b). On d7, nestlings were banded and feces of all siblings were collected, combined and stored at $-20^{\circ} \mathrm{C}$ for analysis of metals. Defecation was induced with a round-ended hairpin. On d7 and d14, nestling wings were measured with a precision of $0.5 \mathrm{~mm}$ with a ruler, total head (bill+head) and tarsus lengths were measured with a digital caliper to the nearest $0.01 \mathrm{~mm}$ and body mass was weighed to the nearest $0.1 \mathrm{~g}$ using a Pesola spring balance. On $\mathrm{d} 9$ and $\mathrm{d} 14$, ca. $75 \mu \mathrm{l}$ of blood were collected in capillary tubes containing sodium-heparin (80 iu/ml, Marienfeld) gotten 
by venipuncture of the ulnar vein. Blood was centrifuged (4400 g, $5 \mathrm{~min}$ ) immediately and hematocrit (HCT, \% of red blood cells, RBC, from total sample volume) was measured. Samples were kept in liquid nitrogen after separating plasma and $\mathrm{RBC}$ until stored at $-80^{\circ} \mathrm{C}$ in the lab. Vitamins were analyzed from plasma collected on d9 and combined per brood ( $\mathrm{n}=64$ broods; Ruiz et al., 2017), whereas d14 plasma from 121 nestlings (usually 2 chicks randomly selected per nest) was used to measure uric acid (UA), Ca and the enzyme activities of creatine kinase (CK) and alkaline phosphatase (ALP) as described by Espín et al. (2016a). Oxidative stress biomarkers were measured from RBC collected at d14 from 120 nestlings $(n=62$ broods).

\section{Analysis of metals, antioxidants and biomarkers of oxidative damage}

Feces from the $\mathrm{d} 7$ nestlings were dried at $45{ }^{\circ} \mathrm{C}$ for $72 \mathrm{~h}$. In order to study metal exposure at brood level, fecal samples from siblings were combined. An inductively coupled plasma optical emission spectrometer (ICP-OES) was used to measure metal concentrations ( $\mathrm{As}, \mathrm{Ca}, \mathrm{Cd}, \mathrm{Cu}$, $\mathrm{Ni}, \mathrm{Pb}, \mathrm{Se}$ and $\mathrm{Zn}$ ). The limit of quantification for $\mathrm{Ca}$ was $1 \mathrm{ppm}$ and $0.01 \mathrm{ppm}$ for all other elements. A Milestone DMA- 80 direct $\mathrm{Hg}$ analyzer was used to analyze total $\mathrm{Hg}$ by atomic absorption spectrophotometry with a limit of detection of $0.005 \mathrm{ng}$. Further details on metal analysis are shown in Espín et al. (2016a). Metal concentrations are expressed in dry weight. The feces mean $( \pm \mathrm{SD})$ water content was $75.7 \% \pm 7.6$.

Antioxidant molecules (tGSH, GSH:GSSG ratio, GST, GPx, SOD, CAT), together with thiobarbituric acid reactive substances (TBARS) and protein carbonylation (PC) as biomarkers reflecting the oxidative damage, were measured from $\mathrm{RBC}$ from 120 great tit nestlings. The analyses were performed in RBC collected at d14 from two randomly selected nestlings per brood. Red blood cells were diluted with $0.9 \% \mathrm{NaCl}$. Proteins $(\mathrm{mg} / \mathrm{ml})$ were measured with the BioRad protein assay (BioRad, Espoo, Finland) and bovine serum albumin (Sigma, USA) as a standard (Bradford, 1976). Glutathione peroxidase, GST and CAT activities were measured using Sigma kits (Sigma Chemicals, St. Louis, USA), and a Fluka kit was used to measure SOD activity (Fluka, Buchs, Germany). Catalase, GST and GPx activities are expressed in 
$\mu \mathrm{mol} / \mathrm{min} / \mathrm{mg}$ of protein, whereas SOD is referred to inhibition percentage (as explained in Stauffer et al., 2018, a higher inhibition rate implies higher SOD activity). The ThioStar ${ }^{\circledR}$ glutathione detection reagent (Arbor Assays, Michigan, USA) was used to measure tGSH (nmol/mg), as well as the ratio of reduced to oxidized glutathione (GSH:GSSG). Reduced glutathione was used as standard (Sigma Chemicals, Missouri, USA). Rainio et al. (2015) provide further technical details on the analysis of CAT, GST, GPx, tGSH, GSH:GSSG and protein carbonylation. Thiobarbituric acid reactive substances were analyzed fluorometrically following the technique described by Espín et al. (2017b) to estimate lipid peroxidation. Samples were analyzed using a microplate reader (each method was done either with EnSpire or Envision, Perkin-Elmer). All samples were analyzed in triplicates (intra-assay coefficient of variability $<15 \%)$. To minimize the sample volume needed, 96- or 384-well microplates were used, reducing reagent volumes accordingly as required. Inter-assay variation was corrected using three control samples with the ratio specific to each particular plate (range 0.8-1.2).

\section{Statistical procedures}

Statistics were carried out with SAS 9.4 statistical package. To study the treatment (Casupplement/control) and zone (polluted/unpolluted) effects, as well as the effect of their interaction on antioxidants and oxidative damage biomarkers, generalized linear mixed models (GLMM) were performed. The effects of Ca levels in plasma and fecal metal concentrations (as a proxy of dietary levels) on biomarkers of oxidative status were also evaluated. A Principal Components Analysis (PCA) for metals (As, $\mathrm{Cd}, \mathrm{Cu}, \mathrm{Hg}, \mathrm{Ni}$ and $\mathrm{Pb}$ ) was carried out after checking that their levels in feces were positively correlated $\left(\mathrm{r}_{\mathrm{s}}=0.38-0.87, \mathrm{p}<0.001\right)$. The

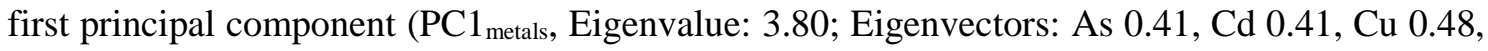
$\mathrm{Hg}$ 0.40, Ni 0.44 and $\mathrm{Pb} 0.28$ ) explained $63 \%$ of the variation in our data, so it was used to indicate the exposure to metals in the models as an explanatory variable together with $\mathrm{Ca}$ in plasma and their interaction. Brood size at $\mathrm{d} 7$ and hatching date were included as possible confounding variables. Finally, GLMMs to assess the associations of the biomarkers of oxidative status with growth, size, number of fledglings and probability of a hatchling to fledge 
(fledging success) were performed. A positive correlation was also found between body size parameters ( $\mathrm{d} 7$ wing, head, tarsus length and body mass; $\left.\mathrm{r}_{\mathrm{p}}=0.65-0.89, \mathrm{p}<0.0001\right)$ and growth parameters (the difference between the measurements of wing, head, tarsus and body mass growth rate on $\mathrm{d} 7$ and $\left.\mathrm{d} 14 ; \mathrm{r}_{\mathrm{p}}=0.31-0.66, \mathrm{p}<0.015\right)$. Thus, we calculated their principal components. The PC1 $1_{\text {size }}$ (Eigenvalue 3.38; Eigenvectors: W7 0.47, H7 0.53, T7 0.51, M7 0.49) explained $85 \%$ of the variation, and the $\mathrm{PC} 1_{\text {growth }}$ (Eigenvalue 2.61; Eigenvectors: wing growth 0.50 , head growth 0.52 , tarsus growth 0.43 , mass growth 0.54 ) explained $65 \%$ of the variation. The biomarkers of oxidative status, zone and their interaction were included in the model as explanatory variables. The interactive effect of biomarkers of oxidative status and treatment on size, growth and fledging success was also evaluated. The effect of each biomarker was tested individually to avoid excessively complicated models.

The residuals of the model were used to check the normality of variables and, when necessary, variables were $\log _{\mathrm{e}}$-transformed for normalization (tGSH, GSH:GSSG ratio, GST, SOD, TBARS). The sampling site $(\mathrm{n}=10)$ was included as a random factor in the models. We used Poisson error distribution for number of fledglings, whereas for fledging success we used binomial error distribution. The residuals of the model were included as a random factor to control overdispersion. The degrees of freedom were adjusted using the Kenward-Roger method. Brood means of nestling measurements were used as independent units to perform a brood-level analysis except for PC, where GLMMs included microplate number and brood as random factors to take inter-plate variation into account. Terms in the model were retained when significant. Non-significant variables were discarded from the model one by one starting with the interactions.

Depending on the normality of data (checked by the Kolmogorov-Smirnov test), Pearson $\left(r_{p}\right)$ or Spearman's $\left(\mathrm{r}_{\mathrm{s}}\right)$ correlation coefficients were studied to check the correlations between response variables. The level of significance was set at $p<0.05$. 


\section{Results}

Table 1 presents the results for biomarkers of oxidative status and damage according to treatment (Ca-supplemented/control) and zone (polluted/unpolluted).

Metal concentrations were higher in feces in the polluted zone, whereas plasma Ca levels were similar between treatment groups and through the pollution gradient (Espín et al., 2016a). Calcium treatment had no effect on the most of the biomarkers: only the activity of CAT was higher in Ca-supplemented nestlings than control birds $(23.79 \pm 3.13$ vs. $22.01 \pm 3.44$ $\mu \mathrm{mol} / \mathrm{min} / \mathrm{mg}$; Table 1).

Great tit nestlings showed higher activities of SOD (35.02 \pm 7.76 vs. $31.54 \pm 5.57 \%$ inhibition; polluted vs. unpolluted zone $)$ and GPx $(0.0096 \pm 0.0034$ vs. $0.0066 \pm 0.0026 \mu \mathrm{mol} / \mathrm{min} / \mathrm{mg})$ in the polluted environment, although the effect was significant only for SOD activity (Table 1). No differences among groups were found in the other biomarkers.

Plasma Ca levels and PC1 $1_{\text {metals }}$ showed an interactive effect on tGSH levels, GSH:GSSG ratio, GPx and GST activities (Table 2, Figure 1). As shown in Figure 1, antioxidant levels change over the range of $\mathrm{PC}_{\text {metals }}$ depending on the $\mathrm{Ca}$ concentrations in plasma. In this sense, increased antioxidants levels (from light to dark) are found with increasing $\mathrm{PC} 11_{\text {metals }}$ when $\mathrm{Ca}$ levels in plasma were > ca. $14 \mathrm{mg} / \mathrm{dl}$, while the opposite trend was found (decreased antioxidant levels - from black to white - with increasing $\mathrm{PC} 1_{\text {metals }}$ ) when Ca concentrations in plasma were $<$ ca. $14 \mathrm{mg} / \mathrm{dl}$.

Most antioxidants correlated with each other and with TBARS levels (Table S1). Negative correlations were found between plasma vitamin A and TBARS or tGSH levels, and between GST activity and vitamin E, while vitamin $\mathrm{D}_{3}$ and PC were positively correlated (Table S1). Glutathione peroxidase was negatively correlated with uric acid, ALP in plasma, growth and size, while CAT activity was positively correlated with ALP in plasma and growth (Table S1). $\mathrm{PC} 11_{\text {metals }}$ were correlated with CK in plasma $(\mathrm{r}=0.41, \mathrm{p}=0.026, \mathrm{n}=29)$ and GPx activity in red 
cells (Table S1). Figure 2 shows a scheme of the relationships between antioxidants, oxidative damage, biochemistry in plasma, metals in feces and nestling size and growth rate.

The number of fledglings was reduced with increasing SOD activity, and nestlings were smaller (PC1size) but grew faster (PC1growth) with increasing TBARS (Table 3). In the polluted zone, nestlings grew (PC1growth) faster with increasing tGSH levels (Table 3, Figure 3a), and the fledging success increased with increasing CAT activity, while in the unpolluted zone, the opposite occurred (Table 3, Figure 3a). In the Ca-supplemented group: the fledging success increased with increasing CAT activity $\left(\mathrm{F}_{\mathrm{ndf}, \mathrm{ddf}}=6.08_{1,51.68}, \mathrm{p}=0.017\right.$, Figure $\left.3 \mathrm{~b}\right)$, higher tGSH levels increased the number of fledglings $\left(F_{\text {ndf,ddf }}=4.96_{1,57.99}, p=0.030\right.$, Figure $\left.3 b\right)$, growth rate tended to be higher with increasing CAT activity $\left(F_{\text {ndf,ddf }}=3.14_{1,58}, p=0.082\right.$, Figure $\left.3 b\right)$, and nestling size decreased with increasing SOD activity $\left(\mathrm{F}_{\text {ndf,ddf }}=6.20_{1,56.47}, \mathrm{p}=0.016\right)$. Finally, an interaction between treatment and GPx was also found on growth rate $\left(F_{\text {ndf,ddf }}=3.80_{1,58}, p=\right.$ 0.056, Figure $3 b$ ), suggesting that growth is negatively associated to GPx activity in the control group but not in the Ca-supplemented group; the treatment was substituted by plasma Ca levels in this model, and $\mathrm{Ca}$ in plasma and GPx activity showed an interaction on growth rate $\left(\mathrm{F}_{\text {ndf,ddf }}=\right.$ $\left.9.28_{1,58}, \mathrm{p}=0.0035\right)$, suggesting that growth is retarded at high GPx activity only when plasma Ca level is low (Figure 4).

\section{Discussion}

\subsection{Effect of metal pollution and Ca supplementation on oxidative status and oxidative damage}

In the present study, the activities of SOD and GPx (not statistically significant) were higher in the polluted area, possibly as a physiological reaction to the augmented oxidative challenge. This antioxidant system up-regulation to balance the increase of ROS production in avian species exposed to metals has been widely reported (Espín et al., 2014a, 2016c; Martínez-Haro et al., 2011; Rainio et al., 2013). In our study, the oxidative stress is probably due to the association of higher metal exposure and the poorer condition of the nestlings growing in the 
polluted environment. Previous results on the same experiment showed that, in the polluted zone, great tits showed higher fecal metal concentrations and smaller size together with a smaller number of fledglings due to lower food quality and quantity (Espín et al., 2016a). In the same line, GPx activity correlated positively with metal levels and negatively with the size and growth of the nestlings.

Overall, antioxidants and oxidative damage showed a limited response to the $\mathrm{Ca}$ treatment, probably because parents were able to find enough natural Ca-rich food items to let nestlings to achieve a proper antioxidant status. Similar results, in the scope of different publications from the same experiment, were obtained for growth, survival, biochemistry and yolk and plasma vitamin levels (Espín et al., 2016a, 2016b; Ruiz et al., 2017). The activity of CAT was higher in Ca-supplemented nestlings, which suggests that Ca could stimulate the activity of this enzyme. The functional mitochondria within avian erythrocytes is essential for energy production during respiration and is a primary source of ROS (Stier et al., 2013). In the mitochondria, Ca homeostasis plays crucial physiological functions in cells: mitochondrial Ca uptake controls the energy production, the patterns of intracellular Ca signals and cell death (Görlach et al., 2015). Increased levels of $\mathrm{Ca}$ stimulate respiratory chain activity and the consequent generation of ROS as by-products (Görlach et al., 2015). Thus, increased levels of Ca could enhance the mitochondrial $\mathrm{Ca}$ cycling activating ROS formation and inducing CAT activity to scavenge ROS. In this sense, global CAT activity and Ca levels in plasma were close to be significantly positively associated $(\mathrm{p}=0.078$; Table 2 and Table $\mathrm{S} 1$ ). This association is particularly evident in the polluted area where nestlings face an increased oxidative challenge (CAT activity and Ca levels in plasma were positively correlated; $\mathrm{r}=0.46, \mathrm{p}=0.01, \mathrm{n}=29$ ).

\subsection{Correlations among antioxidants and biomarkers of oxidative damage}

The close coordination between antioxidant molecules to cope with oxidative stress was reflected by the correlations observed between biomarkers of oxidative damage and antioxidants, as reported in previous studies (Espín et al., 2016c, 2017a; Koivula et al., 2011). The positive correlation found between SOD and GPx is explained by their cooperation 
catalyzing the decomposition of $\mathrm{H}_{2} \mathrm{O}_{2}$ and $\mathrm{O}_{2}-$ respectively (Halliwell and Gutteridge, 2007). Glutathione-S-transferase removes ROS, including $\mathrm{H}_{2} \mathrm{O}_{2}$, through the oxidation of GSH (Valko et al., 2006), thus its positive correlation with SOD may be also interpreted as a collaboration between enzymes. The positive correlations between tGSH and GST, SOD, CAT and TBARS (Fig. 2) can be explained by the different roles of glutathione: scavenging radicals, reduceing lipid peroxides and being a cofactor of different antioxidant enzymes (Valko et al., 2006). The toxic lipid peroxides are also dealt with by antioxidant enzymes to avoid damage to membranes (Somashekaraiah et al., 1992), explaining the positive correlations between TBARS and SOD or GST activities, as found in griffon vultures (Gyps fulvus; Espín et al., 2014a). The clear correlation between TBARS and tGSH indicates that these birds can up-regulate the synthesis of GSH as a reaction to increased oxidative damage to lipids, as previously suggested in pied flycatchers from this experiment (Espín et al., 2017a).

\subsection{Effect of Ca concentrations in plasma against metal-related oxidative stress}

In the light of the results of this study and those found in other publications from the same experiment (Espín et al., 2016a, 2016b; Ruiz et al., 2017), it can be concluded that: (i) few deleterious metal effects were found, mainly because metal concentrations were not high (Espín et al., 2016a), and (ii) nestling growth, biochemistry and antioxidant capacity were not restrained by a deficiency in $\mathrm{Ca}$ availability in great tit. However, this study shows that antioxidant levels (tGSH levels, GSH:GSSG ratio, GPx, GST and CAT activities) change over the range of metal concentrations depending on the plasma Ca levels (or Ca availability in the case of CAT), suggesting that an equilibrium exists between the levels of $\mathrm{Ca}$ in the organism and metal toxicity, and that higher Ca levels stimulate antioxidants and mitigate the impacts of metals. When Ca levels in plasma were higher than ca. $14 \mathrm{mg} / \mathrm{dl}$, increased antioxidant levels were found with increasing metal concentrations in feces. This suggests that birds are able to up-regulate their antioxidant capacity to cope with higher metal exposure when $\mathrm{Ca}$ in plasma is adequate. On the other hand, when Ca concentrations in plasma were lower than ca. $14 \mathrm{mg} / \mathrm{dl}$, decreased antioxidant levels were observed with increasing metals in feces, suggesting that 
metals are prone to inhibit the antioxidant system when Ca levels in plasma are low. Thus, adequate $\mathrm{Ca}$ levels in the organism possibly protect these animals against the oxidative stress induced by metals (Jamakala and Rani, 2012; Prasanthi et al., 2010; Srivastava et al., 2010).

\subsection{Effect of oxidative status and oxidative damage on nestling size, growth and fledging} success

The increased metabolic activity associated with rapid growth may cause oxidative stress (Alonso-Álvarez et al., 2007). This stress may affect physiological and life-history traits such as nestling growth, size or fledging success (Espín et al., 2017a; Losdat et al., 2013; Noguera et al., 2011; Rainio et al., 2013; Saino et al., 2011). Therefore, nestling development is a demanding period that may be even more challenging when birds inhabit environments suffering from both metal pollution and a poorer diet (Eeva et al., 2005; Espín et al., 2016a, 2017a). In this sense, metal-related oxidative processes could explain some effects on nestling growth, size and fledging success. In the present study, nestlings with lower size showed higher TBARS levels, suggesting that the nestlings in worse condition have augmented lipid peroxidation. However, since TBARS levels do not vary between differently polluted zones, metal exposure appears not to suffice to cause oxidative damage to lipids by itself. In addition, a higher growth rate was associated with higher TBARS levels in erythrocytes, showing that nestlings growing faster may have a weaker capacity to resist oxidative damage. This result agrees with a previous study on zebra finch (Taeniopygia guttata) reporting that a negative correlation was found between the resistance of red cells to free radicals and the growth rate (Alonso-Álvarez et al., 2007). An increased growth rate was also associated with enhanced CAT activity and tGSH levels (in the polluted zone), probably reflecting an up-regulation of those antioxidants in response to the oxidative challenge in fast-growing nestlings, particularly in those exposed to metals. Rainio et al. (2013) found that heavier great tit nestlings had higher CAT activity, suggesting that enhanced CAT would remove ROS and would favor the maintenance of GSH in reduced form. This suggests that heavier nestlings can be better equipped to face oxidative stress (Rainio et al., 2013). The positive association between growth rate and CAT activity tended to be stronger in 
the Ca-supplemented group, suggesting that the fast growth, when $\mathrm{Ca}$ availability is good, stimulates ROS generation due to increased metabolic processes, which lead in upregulated CAT activity to balance the oxidative status. The positive correlations observed between growth rate and CAT, and ALP and CAT, support this idea. Similarly, the fledging success was higher with increasing CAT activity in the polluted zone and in the Ca-supplemented group. Losdat et al. (2013) reported that higher pre-fledging red cell resistance to oxidative stress produced better probabilities to fledge in great tits. Therefore, Ca-supplemented nestlings and nestlings with good $\mathrm{Ca}$ levels in the polluted zone, could enhance CAT activity to cope with the ROS generated during fast growth and intense cell respiration (the activity of CAT was higher in Casupplemented nestlings, and $\mathrm{Ca}$ in plasma and CAT activity correlate positively in the polluted area), and improve their probability to fledge. Interestingly, it was also found that Casupplemented nestlings improved their growth with increasing GPx activity compared with the control group, and growth rate was retarded at increasing GPx activity only when plasma $\mathrm{Ca}$ level was low. In general, the interactions found between Ca treatment and antioxidants (CAT, GPx and tGSH) on nestling parameters suggest that $\mathrm{Ca}$ supplementation improves fledging success, number of fledglings and nestling growth when antioxidants are up-regulated in a situation of oxidative challenge.

Finally, increased number of fledglings was associated with decreased SOD activity. Researchers have reported higher oxidative stress in nestlings with a higher number of siblings. In this sense, eagle owl (Bubo bubo) nestlings from larger broods showed lower GPx and CAT activities (Espín et al., 2014b), and common starlings (Sturnus vulgaris) raised in broods that had been experimentally enlarged showed a reduced antioxidant power (Bourgeon et al., 2011), which could be related to sibling competition for space and food (Koivula et al., 2011).

\section{Conclusions}

This study presents few negative effects of metal pollution on the antioxidant status of great tit nestlings, mainly because metal concentrations were relatively low (Berglund et al., 2012). Although $\mathrm{Ca}$ availability was not notably constraining the antioxidant capacity of great tit 
nestlings, our results suggest that $\mathrm{Ca}$ levels in the organism play an important role in the ability of the individual to cope with metal oxidative stress. Therefore, $\mathrm{Ca}$ availability should be considered in future studies evaluating metal exposure and effects on wild birds. The close coordination between antioxidant molecules to protect against oxidative stress was reflected by the correlations observed between biomarkers of oxidative damage and antioxidants. The antioxidant molecules, conditioned by metal pollution and Ca levels in the organism, are related with nestling size, growth and reproductive output.

\section{Acknowledgements}

We thank Miia Rainio and Jorma Nurmi for their collaboration in the field. Our study was financed by the University of Turku Graduate School (to PS-V), Societas pro Fauna et Flora Fennica (to PS-V), Fundación Séneca - Agencia de Ciencia y Tecnología de la Región de Murcia (20031/SF/16 to SE and MASCA'2014 Project 19481/PI/14) and the Academy of Finland (project 265859 to TE). Licenses from the Centre for Economic Development, Transport and the Environment, ELY Centre Southwest Finland (VARELY/319/07.01/2014) and the Animal Experiment Committee of the State Provincial Office of Southern Finland (ESAVI/1650/04.10.03/2012) were obtained to perform the experiment. All applicable national and institutional guidelines for the care and use of animals were followed. The authors declare that they have no conflict of interest.

\section{References}

Abdel-Hameid, N.-A.H. (2009). A Protective Effect of Calcium Carbonate Against Arsenic Toxicity of the Nile Catfish, Clarias gariepinus. Turk. J. Fish. Aquat. Sci. 9.

Alonso-Álvarez, C., Bertrand, S., Faivre, B., and Sorci, G. (2007). Increased susceptibility to oxidative damage as a cost of accelerated somatic growth in zebra finches. Funct. Ecol. 21, 873-879.

Berglund, Å.M.M., Sturve, J., Förlin, L., and Nyholm, N.E.I. (2007). Oxidative stress in pied flycatcher (Ficedula hypoleuca) nestlings from metal contaminated environments in northern Sweden. Environ. Res. 105, 330-339. 
Berglund, A.M.M., Rainio, M.J., and Eeva, T. (2012). Decreased metal accumulation in passerines as a result of reduced emissions. Environ. Toxicol. Chem. SETAC 31, 1317-1323.

Bourgeon, S., Guindre-Parker, S., and Williams, T.D. (2011). Effects of sibling competition on growth, oxidative stress, and humoral immunity: a two-year brood-size manipulation. Physiol. Biochem. Zool. PBZ 84, 429-437.

Bradford, M.M. (1976). A rapid and sensitive method for the quantitation of microgram quantities of protein utilizing the principle of protein-dye binding. Anal. Biochem. 72, 248-254.

Burger, J., and Gochfeld, M. (2000). Effects of lead on birds (Laridae): a review of laboratory and field studies. J. Toxicol. Environ. Health B Crit. Rev. 3, 59-78.

Dauwe, T., Snoeijs, T., Bervoets, L., Blust, R., and Eens, M. (2006). Calcium availability influences lead accumulation in a passerine bird. Anim. Biol. 56, 289-298.

Deeming, D.C., and Pike, T.W. (2013). Embryonic growth and antioxidant provision in avian eggs. Biol. Lett. 9, 20130757.

Eeva, T., Ryömä, M., and Riihimäki, J. (2005). Pollution-related changes in diets of two insectivorous passerines. Oecologia 145, 629-639.

Eeva, T., Rainio, K., and Suominen, O. (2010). Effects of pollution on land snail abundance, size and diversity as resources for pied flycatcher, Ficedula hypoleuca. Sci. Total Environ. 408, 4165-4169.

Espín, S., Martínez-López, E., Jiménez, P., María-Mojica, P., and García-Fernández, A.J. (2014a). Effects of heavy metals on biomarkers for oxidative stress in Griffon Vulture (Gyps fulvus). Environ. Res. 129, 59-68.

Espín, S., Martínez-López, E., León-Ortega, M., Martínez, J.E., and García-Fernández, A.J. (2014b). Oxidative stress biomarkers in Eurasian Eagle owls (Bubo bubo) in three different scenarios of heavy metal exposure. Environ. Res. 131, 134-144.

Espín, S., Ruiz, S., Sánchez-Virosta, P., and Eeva, T. (2016a). Effects of calcium supplementation on growth and biochemistry in two passerine species breeding in a Ca-poor and metal-polluted area. Environ. Sci. Pollut. Res. 23, 9809-9821.

Espín, S., Ruiz, S., Sánchez-Virosta, P., Salminen, J.-P., and Eeva, T. (2016b). Effects of experimental calcium availability and anthropogenic metal pollution on eggshell characteristics and yolk carotenoid and vitamin levels in two passerine birds. Chemosphere 151, 189-201.

Espín, S., Martínez-López, E., Jiménez, P., María-Mojica, P., and García-Fernández, A.J. (2016c). Interspecific differences in the antioxidant capacity of two Laridae species exposed to metals. Environ. Res. 147, 115-124.

Espín, S., Ruiz, S., Sánchez-Virosta, P., Lilley, T., and Eeva, T. (2017a). Oxidative status in relation to metal pollution and calcium availability in pied flycatcher nestlings - A calcium manipulation experiment. Environ. Pollut. 229, 448-458.

Espín, S., Sánchez-Virosta, P., García-Fernández, A.J., and Eeva, T. (2017b). A microplate adaptation of the thiobarbituric acid reactive substances assay to determine lipid peroxidation fluorometrically in small sample volumes. Rev. Toxicol. 34, 94-98.

Finkel, T., and Holbrook, N.J. (2000). Oxidants, oxidative stress and the biology of ageing. Nature 408, 239-247.

Flora, S.J.S., Mittal, M., and Mehta, A. (2008). Heavy metal induced oxidative stress \& its possible reversal by chelation therapy. Indian J. Med. Res. 128, 501-523. 
Florea, A.-M., and Büsselberg, D. (2008). Arsenic trioxide in environmentally and clinically relevant concentrations interacts with calcium homeostasis and induces cell type specific cell death in tumor and non-tumor cells. Toxicol. Lett. 179, 34-42.

Florea, A.-M., Yamoah, E.N., and Dopp, E. (2005). Intracellular Calcium Disturbances Induced by Arsenic and Its Methylated Derivatives in Relation to Genomic Damage and Apoptosis Induction. Environ. Health Perspect. 113, 659-664.

García-Fernández, A.J., Bayoumi, A.E., Pérez-Pertejo, Y., Motas, M., Reguera, R.M., Ordóñez, C., Balaña-Fouce, R., and Ordóñez, D. (2002). Alterations of the glutathione-redox balance induced by metals in CHO-K1 cells. Comp. Biochem. Physiol. Toxicol. Pharmacol. CBP 132, 365-373.

Görlach, A., Bertram, K., Hudecova, S., and Krizanova, O. (2015). Calcium and ROS: A mutual interplay. Redox Biol. 6, 260-271.

Graveland, J. (1995). Calcium limitation in the reproduction of forest passerines in relation to snail abundance and soil acidification. Netherlands Institute of Ecology, Centre for Terrestrial Ecology.

Graveland, J. (1996). Avian eggshell formation in calcium-rich and calcium-poor habitats: importance of snail shells and anthropogenic calcium sources. Can. J. Zool. 74, 1035-1044.

Halliwell, B., and Gutteridge, J. (2007). Free Radicals in Biology and Medicine (Oxford University Press, USA).

Jamakala, O., and Rani, U.A. (2012). Protective role of trace elements against cadmium induced alterations in the selected oxidative stress enzymes in liver and kidney of fresh water teleost, Oreochromis mossambicus (Tilapia). Int. J. Pharm. Pharm. Sci. 4, 303-310.

Koivula, M.J., and Eeva, T. (2010). Metal-related oxidative stress in birds. Environ. Pollut. 158, 23592370 .

Koivula, M.J., Kanerva, M., Salminen, J.-P., Nikinmaa, M., and Eeva, T. (2011). Metal pollution indirectly increases oxidative stress in great tit (Parus major) nestlings. Environ. Res. 111, 362-370.

Lambrechts, M.M., Adriaensen, F., Ardia, D.R., Artemyev, A.V., Atiénzar, F., Bańbura, J., Barba, E., Bouvier, J.-C., Camprodon, J., Cooper, C.B., et al. (2010). The Design of Artificial Nestboxes for the Study of Secondary Hole-Nesting Birds: A Review of Methodological Inconsistencies and Potential Biases. Acta Ornithol. 45, 1-26.

Losdat, S., Helfenstein, F., Blount, J.D., Marri, V., Maronde, L., and Richner, H. (2013). Nestling erythrocyte resistance to oxidative stress predicts fledging success but not local recruitment in a wild bird. Biol. Lett. 9, 20120888.

Marettová, E., Maretta, M., and Legáth, J. (2015). Toxic effects of cadmium on testis of birds and mammals: A review. Anim. Reprod. Sci. 155, 1-10.

Martínez-Haro, M., Green, A.J., and Mateo, R. (2011). Effects of lead exposure on oxidative stress biomarkers and plasma biochemistry in waterbirds in the field. Environ. Res. 111, 530-538.

McGraw, K.J. (2011). Avian Antioxidants and Oxidative Stress: Highlights from Studies of Food, Physiology, and Feathers. In Studies on Veterinary Medicine, L. Mandelker, and P. Vajdovich, eds. (Humana Press), pp. 161-174.

Noguera, J.C., Kim, S.-Y., and Velando, A. (2011). Pre-fledgling oxidative damage predicts recruitment in a long-lived bird. Biol. Lett. rsbl20110756.

Pounds, J.G. (1984). Effect of lead intoxication on calcium homeostasis and calcium-mediated cell function: a review. Neurotoxicology 5, 295-331. 
Prasanthi, R.P.J., Devi, C.B., Basha, D.C., Reddy, N.S., and Reddy, G.R. (2010). Calcium and zinc supplementation protects lead $(\mathrm{Pb})$-induced perturbations in antioxidant enzymes and lipid peroxidation in developing mouse brain. Int. J. Dev. Neurosci. Off. J. Int. Soc. Dev. Neurosci. 28, 161-167.

Rai, A.N., Srivastava, S., Paladi, R., and Suprasanna, P. (2012). Calcium supplementation modulates arsenic-induced alterations and augments arsenic accumulation in callus cultures of Indian mustard (Brassica juncea (L.) Czern.). Protoplasma 249, 725-736.

Rainio, M.J., Kanerva, M., Salminen, J.-P., Nikinmaa, M., and Eeva, T. (2013). Oxidative status in nestlings of three small passerine species exposed to metal pollution. Sci. Total Environ. 454-455, 466473.

Rainio, M.J., Eeva, T., Lilley, T., Stauffer, J., and Ruuskanen, S. (2015). Effects of early-life lead exposure on oxidative status and phagocytosis activity in great tits (Parus major). Comp. Biochem. Physiol. Toxicol. Pharmacol. CBP 167, 24-34.

Reynolds, S.J., Mänd, R., and Tilgar, V. (2004). Calcium supplementation of breeding birds: directions for future research. Ibis $146,601-614$.

Ruiz, S.R., Espín, S., Sánchez-Virosta, P., Salminen, J.-P., Lilley, T.M., and Eeva, T. (2017). Vitamin profiles in two free-living passerine birds under a metal pollution gradient - A calcium supplementation experiment. Ecotoxicol. Environ. Saf. 138, 242-252.

Saino, N., Caprioli, M., Romano, M., Boncoraglio, G., Rubolini, D., Ambrosini, R., Bonisoli-Alquati, A., and Romano, A. (2011). Antioxidant Defenses Predict Long-Term Survival in a Passerine Bird. PLOS ONE 6, e19593.

Sánchez-Virosta, P., Espín, S., García-Fernández, A.J., and Eeva, T. (2015). A review on exposure and effects of arsenic in passerine birds. Sci. Total Environ. 512-513, 506-525.

Sánchez-Virosta, P., Espín, S., Ruiz, S., Salminen, J.-P., García-Fernández, A.J., and Eeva, T. (2018). Experimental manipulation of dietary arsenic levels in great tit nestlings: Accumulation pattern and effects on growth, survival and plasma biochemistry. Environ. Pollut. 233, 764-773.

Scheuhammer, A.M. (1996). Influence of reduced dietary calcium on the accumulation and effects of lead, cadmium, and aluminum in birds. Environ. Pollut. 94, 337-343.

Somashekaraiah, B.V., Padmaja, K., and Prasad, A.R. (1992). Lead-induced lipid peroxidation and antioxidant defense components of developing chick embryos. Free Radic. Biol. Med. 13, 107-114.

Srivastava, D., Subramanian, R.B., Madamwar, D., and Flora, S.J.S. (2010). Protective effects of selenium, calcium, and magnesium against arsenic-induced oxidative stress in male rats. Arh. Hig. Rada Toksikol. 61, 153-159.

Stauffer, J., Panda, B., and Ilmonen, P. (2018). Telomere length, sibling competition and development of antioxidant defense in wild house mice. Mech. Ageing Dev. 169, 45-52.

Stier, A., Bize, P., Schull, Q., Zoll, J., Singh, F., Geny, B., Gros, F., Royer, C., Massemin, S., and Criscuolo, F. (2013). Avian erythrocytes have functional mitochondria, opening novel perspectives for birds as animal models in the study of ageing. Front. Zool. 10, 33.

Suzuki, N., Yamamoto, M., Watanabe, K., Kambegawa, A., and Hattori, A. (2004). Both mercury and cadmium directly influence calcium homeostasis resulting from the suppression of scale bone cells: the scale is a good model for the evaluation of heavy metals in bone metabolism. J. Bone Miner. Metab. 22, 439-446.

Suzuki, Y., Chao, S.H., Zysk, J.R., and Cheung, W.Y. (1985). Stimulation of calmodulin by cadmium ion. Arch. Toxicol. 57, 205-211. 
Valko, M., Rhodes, C.J., Moncol, J., Izakovic, M., and Mazur, M. (2006). Free radicals, metals and antioxidants in oxidative stress-induced cancer. Chem. Biol. Interact. 160, 1-40.

Wolfe, M.F., Schwarzbach, S., and Sulaiman, R.A. (1998). Effects of mercury on wildlife: A comprehensive review. Environ. Toxicol. Chem. 17, 146-160. 
Table 1. Mean ( \pm SD) antioxidants and oxidative damage biomarker levels in red cells of 14-day old great tit nestlings for Ca-supplem unpolluted zone, and generalized linear mixed models for the effects of zone and Ca treatment on oxidative stress biomarkers

\begin{tabular}{|c|c|c|c|c|c|c|c|}
\hline Zone & Treatment & & $\begin{array}{l}\text { tGSH }^{\mathrm{b}} \\
\text { (nmol/mg) }\end{array}$ & $\begin{array}{l}\text { GSH:GSSG } \\
\text { ratiob }^{b}\end{array}$ & $\begin{array}{l}\text { GPx } \\
(\mu \mathrm{mol} / \mathrm{min} / \mathrm{mg})\end{array}$ & $\begin{array}{l}\text { GST }^{\mathrm{b}} \\
(\mu \mathrm{mol} / \mathrm{min} / \mathrm{mg})\end{array}$ & $\begin{array}{l}\text { CAT } \\
(\mu \mathrm{mol} / \mathrm{min} / \mathrm{mg}\end{array}$ \\
\hline \multirow[t]{2}{*}{ Polluted } & Ca-supplemented $(n=13)$ & Mean \pm SD & $30.66 \pm 13.11$ & $0.75 \pm 0.40$ & $0.0093 \pm 0.0036$ & $0.0034 \pm 0.0020$ & $24.14 \pm 4.01$ \\
\hline & Control $(n=16)$ & Mean \pm SD & $31.04 \pm 11.1$ & $0.74 \pm 0.18$ & $0.0098 \pm 0.0034$ & $0.0026 \pm 0.0017$ & $22.10 \pm 1.89$ \\
\hline \multirow[t]{2}{*}{ Unpolluted } & Ca-supplemented $(n=13)$ & Mean \pm SD & $42.3 \pm 24.43$ & $0.70 \pm 0.14$ & $0.0069 \pm 0.0027$ & $0.0033 \pm 0.0024$ & $23.44 \pm 2.02$ \\
\hline & Control $(n=20)$ & Mean \pm SD & $30.6 \pm 7.86$ & $0.75 \pm 0.22$ & $0.0064 \pm 0.0026$ & $0.0026 \pm 0.0011$ & $21.95 \pm 4.36$ \\
\hline \multirow{5}{*}{ GLMMa $^{\mathbf{a}}$} & Zone & $F_{\text {ndf,ddf }}$ & $0.57_{1,8.405}$ & $0.04_{1,9.125}$ & $4.21_{1,6.38}$ & $0.23_{1,59}$ & $0.20_{1,59}$ \\
\hline & & $\mathrm{p}$ & 0.471 & 0.846 & 0.083 & 0.633 & 0.659 \\
\hline & Treatment & $F_{\text {ndf,ddf }}$ & $1.51_{1,56.93}$ & $0.69_{1,58.33}$ & $0.02_{1,52.53}$ & $1.63_{1,60}$ & $4.341,60$ \\
\hline & & $\mathrm{p}$ & 0.224 & 0.411 & 0.887 & 0.206 & 0.042 \\
\hline & Zone $x$ Treatment & $F_{\text {ndf,ddf }}$ & $2.06_{1,55.3}$ & $0.01_{1,56.41}$ & $0.39_{1,51.7}$ & $0.82_{1,58}$ & $0.11_{1,58}$ \\
\hline
\end{tabular}

${ }^{a}$ GLMM with normal error distribution. The site was included as random factor in all the models. GLMMs were done at the brood le measurements as independent units, except for PC where we performed GLMMs including brood and microplate number as random shown in bold.

${ }^{b}$ The variables were $\log _{e}$-transformed before GLMM analysis.

${ }^{c} N=$ number of broods, except for PC where N=number of samples. $t G S H=$ total glutathione, GSH:GSSG ratio=ratio of reduc $G P x=$ glutathione peroxidase, GST=glutathione-S-transferase, CAT=catalase, $S O D=$ superoxide dismutase, TBARS=lipid peroxid reactive substances, $P C=$ protein carbonylation. 
Table 2. Generalized linear mixed models $\mathrm{s}^{\mathrm{a}}$ for variation in antioxidants and biomarkers of oxidative damage of 14-day old great tit nestlin Harjavalta, Finland

\begin{tabular}{|c|c|c|c|c|c|c|c|c|c|c|c|c|c|}
\hline \multirow[t]{2}{*}{$\begin{array}{l}\text { Response } \\
\text { variable } \\
\end{array}$} & \multicolumn{3}{|l|}{ PC1 $1_{\text {metals }}$} & \multicolumn{3}{|c|}{ Ca in plasma } & \multicolumn{3}{|c|}{$\mathrm{PC1}_{\text {metals }} \mathrm{x} \mathbf{C a}$ in plasma } & \multicolumn{3}{|c|}{ Hatching date } & \multirow{2}{*}{$\begin{array}{l}\text { Brood s } \\
F_{\text {ndf,ddf }} \\
\end{array}$} \\
\hline & $F_{\text {ndf,ddf }}$ & $\mathrm{p}$ & Est & ndff,ddf & $\mathrm{p}$ & Est & $F_{\text {ndf,ddf }}$ & $\mathrm{p}$ & Est & $F_{\text {ndf,ddf }}$ & $\mathrm{p}$ & Est & \\
\hline $\mathrm{tGSH}^{\mathrm{b}}$ & $5.62_{1,55.33}$ & 0.021 & -0.410 & & 68 & 0.03 & 510 & 7 & 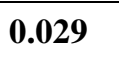 & $0.51_{1,49.95}$ & 79 & -0.0 & $0.08_{1,55}$ \\
\hline $\begin{array}{l}\text { GSH:GSSG } \\
\text { ratio }^{\text {b }}\end{array}$ & $.021,58$ & 0.029 & -0.292 & $1.87_{1,58}$ & 177 & 0.023 & 58 & & 0.023 & $2.26_{1,57}$ & & 0.011 & $0.17_{1,56}$ \\
\hline GPx & $6.47_{1,50.26}$ & 0.014 & -0.003 & $0.05_{1,49.43}$ & 0.822 & -0.00003 & $11.21_{1,48.27}$ & 0.002 & 0.0003 & $1.18_{1,53.91}$ & 0.282 & 0.000 & $0.03_{1,54}$ \\
\hline $\mathrm{GST}^{\mathrm{b}}$ & $8.531,55.1$ & 0.005 & -0.927 & $6.161,54.86$ & 0.016 & 0.104 & $8.361,53.38$ & 0.006 & 0.067 & $3.79_{1,46.15}$ & 0.058 & 0.036 & $2.59_{1,54 .}$ \\
\hline CAT & $0.79_{1,58}$ & 0.378 & 0.197 & $3.22_{1,60}$ & 0.078 & 0.377 & $0.18_{1,57}$ & 0.677 & 0.051 & $0.07_{1,56}$ & 0.792 & -0.024 & $1.73_{1,59}$ \\
\hline $\mathrm{SOD}^{\mathrm{b}}$ & $0.72_{1,58}$ & 0.398 & 0.010 & $1.30_{1,59}$ & 0.260 & 0.013 & $3.68_{1,57}$ & 0.060 & 0.012 & $0.16_{1,56}$ & 0.694 & -0.002 & $6.94_{1,60}$ \\
\hline $\mathrm{TBARS}^{\mathrm{b}}$ & $0.67_{1,16.34}$ & 0.424 & -0.023 & $0.04_{1,55.97}$ & 0.847 & -0.005 & $1.47_{1,51.79}$ & 0.231 & 0.015 & $7.98_{1,53.73}$ & 0.007 & -0.024 & $1.30_{1,53}$ \\
\hline $\mathrm{PC}$ & $1.30_{1,56.16}$ & 0.259 & -0.017 & $0.38_{1,104.8}$ & 0.539 & 0.007 & $1.72_{1,103.7}$ & 0.193 & 0.008 & $0.06_{1,74.42}$ & 0.814 & -0.001 & $0.01_{1,63}$ \\
\hline
\end{tabular}

${ }^{\mathrm{a}}$ GLMMs with normal error distribution. The site was included as random factor in all the models. Terms left in the final model are shown ${ }^{\mathrm{b}}$ The variables were log-transformed before analysis. $t G S H=$ total glutathione, GSH:GSSG ratio=ratio of reduced glutathione to g disulfide, GPX=glutathione peroxidase, GST=glutathione-S-transferase, CAT=catalase, SOD=superoxide dismutase, TBARS=lipid per estimated as thiobarbituric acid-reactive substances, $P C=$ protein carbonylation, $P C 1_{\text {metals }}=$ first principal component of six metals $($ As, $C$ $\mathrm{Pb}$ and $\mathrm{Hg}$ ) in feces. 
Table 3. Effect of oxidative stress biomarkers and zone on fledgling number, fledging success, nestling size and growth rate in great tit

\begin{tabular}{|c|c|c|c|c|c|c|c|c|}
\hline \multirow[t]{2}{*}{ Effect } & \multicolumn{2}{|c|}{ Fledgling number ${ }^{\mathrm{a}}$} & \multicolumn{2}{|c|}{ Fledging success ${ }^{\mathrm{b}}$} & \multicolumn{2}{|c|}{$P C 1_{\text {size }}(d 7)^{c}$} & \multicolumn{2}{|c|}{$\mathrm{PC} 1_{\text {growth }}{ }^{\mathrm{c}}$} \\
\hline & $F_{\text {ndf,ddf }}$ & $\mathrm{p}$ & $F_{\text {ndf,ddf }}$ & $\mathrm{p}$ & $F_{\text {ndf,ddf }}$ & $\mathrm{p}$ & $F_{n d f, d d f}$ & $\mathrm{p}$ \\
\hline Zone & $8.21,65$ & 0.0056 & $4.21,65$ & 0.0446 & 13.0 1,9.35 & 0.0053 & $3.861,58$ & 0.0542 \\
\hline tGSH & $0.14_{1,59}$ & 0.7051 & $0.071,59$ & 0.7952 & $3.87_{1,59}$ & 0.0539 & $6.091,58$ & 0.0165 \\
\hline Zone $\mathrm{x}$ tGSH & $0.1_{1,58}$ & 0.7525 & $2.6_{1,58}$ & 0.1124 & $0.221,57.13$ & 0.6408 & $4.244_{1,58}$ & 0.0441 \\
\hline Zone & $8.21,65$ & 0.0056 & $4.21,65$ & 0.0446 & 13.0 1,9.35 & 0.0053 & $0.2_{1,59}$ & 0.659 \\
\hline GSH:GSSG & $0.281,58.95$ & 0.5994 & $0_{1,59}$ & 0.9744 & $1.261,56.92$ & 0.266 & $0.73_{1,60}$ & 0.3956 \\
\hline Zone x GSH:GSSG & $1.52_{1,58}$ & 0.2228 & $1.37_{1,58}$ & 0.246 & $0.099_{1,55.47}$ & 0.7702 & $0.72_{1,58}$ & 0.4001 \\
\hline Zone & $8.21,65$ & 0.0056 & $4.21,65$ & 0.0446 & $13.01,9.35$ & 0.0053 & $0.19_{1,59}$ & 0.6643 \\
\hline GPx & $2.66_{1,59}$ & 0.108 & $3.271,59$ & 0.0755 & $0.52 \quad 1,54.96$ & 0.4718 & $3.44_{1,60}$ & 0.0685 \\
\hline Zone $\mathrm{x}$ GPx & $2.77_{1,58}$ & 0.1017 & $2.15_{1,58}$ & 0.148 & $0.98_{1,52.26}$ & 0.3276 & $0.91_{1,58}$ & 0.3434 \\
\hline Zone & $8.21,65$ & 0.0056 & $4.21,65$ & 0.0446 & $13.01,9.35$ & 0.0053 & $0.18_{1,59}$ & 0.6696 \\
\hline GST & $0.17_{1,59}$ & 0.6808 & $0.01_{1,59}$ & 0.941 & $1.2_{1,58.78}$ & 0.2782 & $0.31_{1,60}$ & 0.5771 \\
\hline Zone x GST & $0.24_{1,58}$ & 0.6267 & $1.65_{1,58}$ & 0.2036 & $0.08_{1,57.87}$ & 0.7811 & $1.71_{1,58}$ & 0.1963 \\
\hline Zone & $8.21,65$ & 0.0056 & $11.41,58$ & 0.0013 & 13.0 1,9.35 & 0.0053 & $0.34_{1,59}$ & 0.5617 \\
\hline CAT & $1.39_{1,59}$ & 0.2431 & $0.051,58$ & 0.828 & $1.48_{1,56.04}$ & 0.2295 & $4.541,60$ & 0.0372 \\
\hline Zone x CAT & $1.14_{1,58}$ & 0.2904 & $9.321,58$ & 0.0034 & $1.33 \quad 1,54.60$ & 0.253 & $3.41,58$ & 0.0702 \\
\hline Zone & $11.4_{1,59}$ & 0.0013 & $4.21,65$ & 0.0446 & $13.01,9.35$ & 0.0053 & $0.15_{1,61}$ & 0.698 \\
\hline SOD & $5.461,59$ & 0.0229 & $2.46_{1,59}$ & 0.122 & $3.051,55.92$ & 0.0865 & $0.05_{1,59}$ & 0.8223 \\
\hline Zone x SOD & $0.28_{1,58}$ & 0.6006 & $0.31_{1,58}$ & 0.5794 & $2.931,54.9$ & 0.0926 & $0.79_{1,58}$ & 0.3767 \\
\hline Zone & $8.21,65$ & 0.0056 & $4.21,65$ & 0.0446 & $17.3_{1,9.05}$ & 0.0024 & $0.471,59$ & 0.4972 \\
\hline TBARS & $0.2_{1,59}$ & 0.6538 & $0_{1,59}$ & 0.9946 & $9.131,58.87$ & 0.0037 & $5.091,60$ & $\mathbf{0 . 0 2 7 7}$ \\
\hline Zone $\mathrm{x}$ TBARS & $0.01_{1,58}$ & 0.9193 & $0.37_{1,58}$ & 0.5449 & $0_{1,57.81}$ & 0.9484 & $0.25_{1,58}$ & 0.6211 \\
\hline Zone & $8.21,65$ & 0.0056 & $4.21,65$ & 0.0446 & 13.0 1,9.35 & 0.0053 & $0.54_{1,58}$ & 0.4655 \\
\hline $\mathrm{PC}$ & $0.581,56.51$ & 0.4478 & $3.061,58$ & 0.0855 & $1.54_{1,55.29}$ & 0.2198 & $1.55_{1,59}$ & 0.2182 \\
\hline Zone x PC & $0.83_{1,55.70}$ & 0.3674 & $0.01_{1,57}$ & 0.9174 & $0.22 \quad 1,53.96$ & 0.6441 & $0.64_{1,57}$ & 0.4277 \\
\hline
\end{tabular}

Terms left in the final model are shown in bold. Fledging success (probability of a hatchling to fledge), $\mathrm{PC} 1_{\text {size }}$ (first principal component of wing, tarsus and head length and body mass at d7), $\mathrm{PC} 1_{\text {growth }}$ (first principal component of wing, mass, tarsus and head growth), tGSH = total Glutathione, GSH:GSSG ratio = ratio of reduced glutathione to glutathione disulfide, GPx = glutathione peroxidase, GST $=$ glutathione-S-transferase, $\mathrm{SOD}=$ superoxide dismutase, TBARS = lipid peroxidation, estimated as thiobarbituric acid-reactive substances, $\mathrm{PC}=$ protein carbonylation

${ }^{\mathrm{a}}$ GLMMs with Poisson error distribution.

${ }^{\mathrm{b}} \mathrm{GLMMs}$ with binomial error distribution.

'LMMs with normal distribution. 


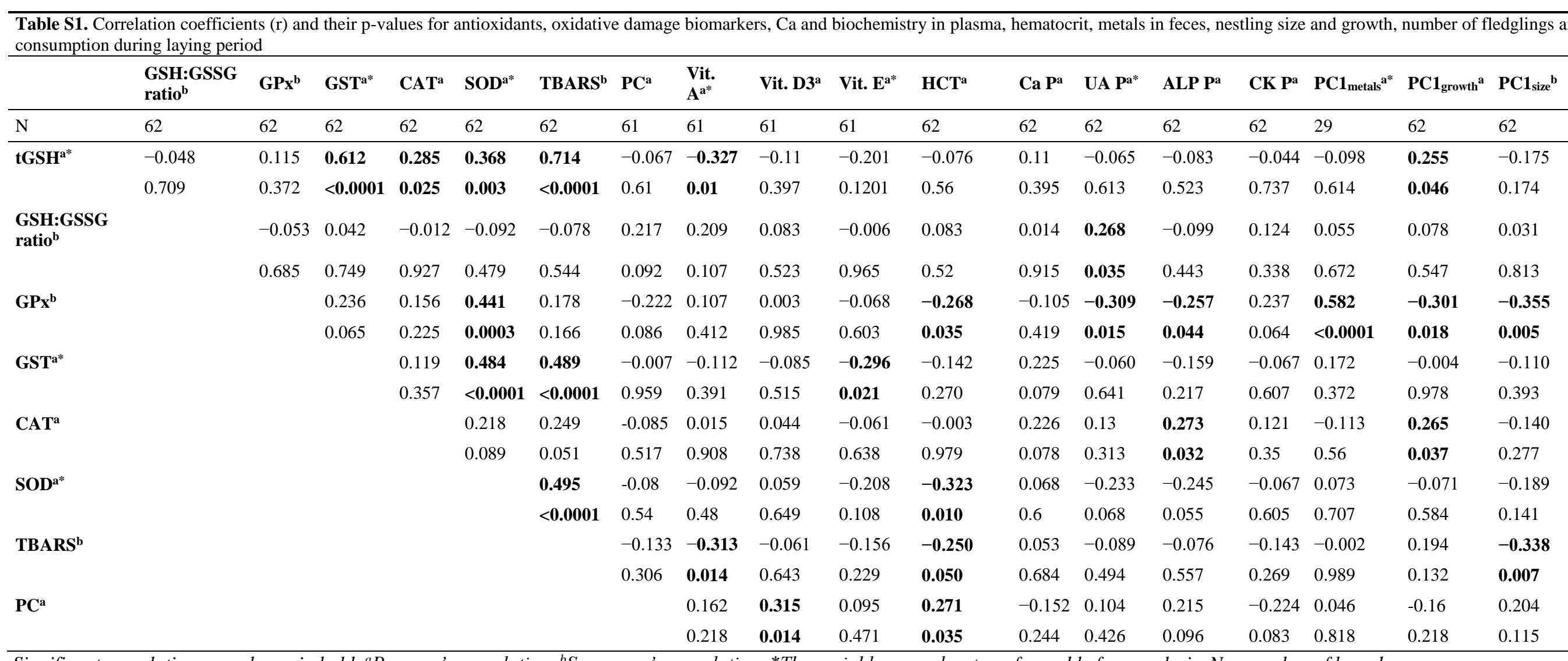

Significant correlations are shown in bold. ${ }^{a}$ Pearson's correlation, ${ }^{b}$ Spearman's correlation. $*$ The variables were log-transformed before analysis. $N=$ number of broods.

$t G S H=$ total glutathione (d14), GSH:GSSG ratio=ratio of reduced glutathione to glutathione disulfide (d14), GPx=glutathione peroxidase (d14), GST=glutathione-Stransferase (d14), CAT=catalase (d14), SOD=superoxide dismutase (d14), TBARS=thiobarbituric acid-reactive substances $(d 14)$, PC=protein carbonylation $(d 14)$, Vit $=$ vitamins A, D3 and E in plasma (d9), HCT=hematocrit (d14), Ca P=calcium in plasma (d14), UA P=uric acid in plasma (d14), ALP P=alkaline phosphatase in plasma (d14), CK P=creatine kinase in plasma (d14), PC1 metals $=$ first principal component of six metals $(\mathrm{As}, \mathrm{Cd}, \mathrm{Cu}, \mathrm{Ni}, \mathrm{Pb}$ and $\mathrm{Hg})$ in feces $(\mathrm{d} 7), \mathrm{PC} 1_{\text {growth }}=\mathrm{first}$ principal component of growth parameters (wing, tarsus, head and body mass growth rate), $P C 1_{\text {size }}=$ first principal component of body size parameters (wing, tarsus, head length and body mass on d7), FL=number of fledglings, $C a$ cons. laying=calcium consumption during the laying period. 


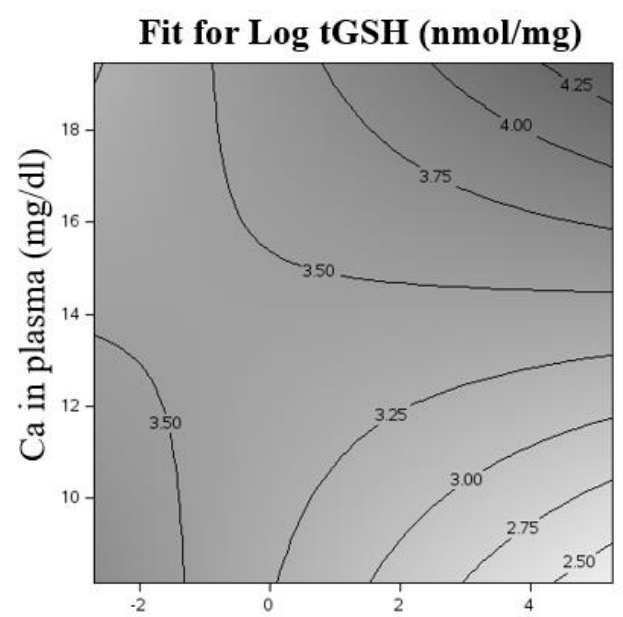

Fit for GPx $(\mu \mathrm{mol} / \mathrm{min} / \mathrm{mg})$

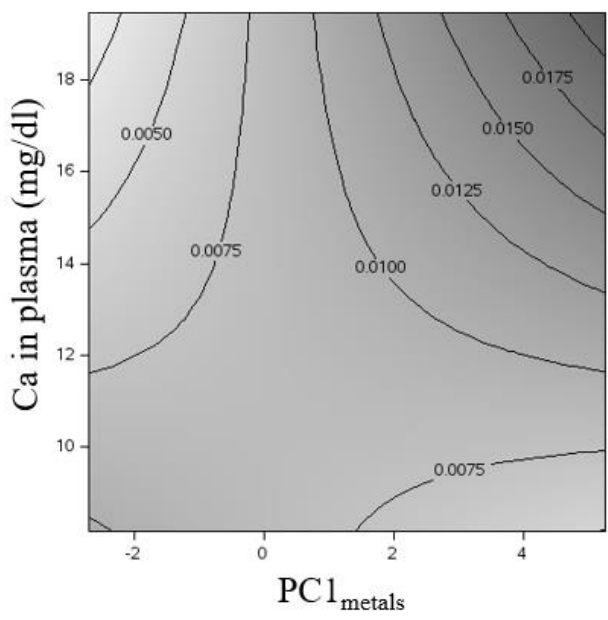

Fit for Log GSH:GSSG ratio

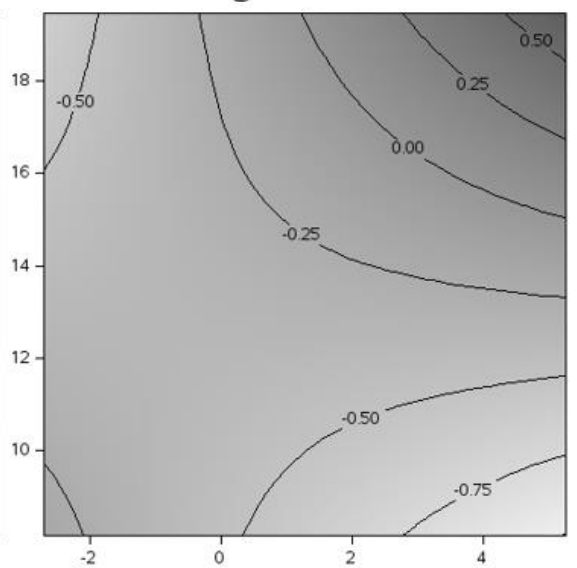

Fit for Log GST $(\mu \mathrm{mol} / \mathrm{min} / \mathrm{mg})$

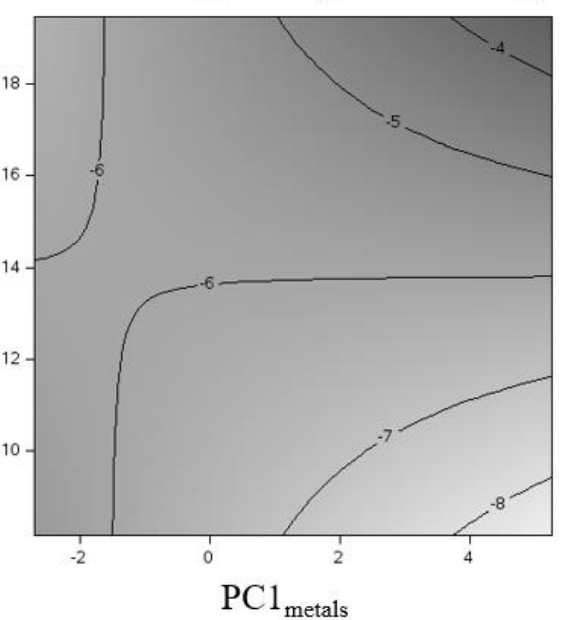

Figure 1. Contour plots for tGSH, GSH:GSSG ratio, GPx and GST activity in red cells of great tit nestlings displaying the interaction between $\mathrm{PC}_{\text {metals }}$ (first principal component of $\mathrm{As}, \mathrm{Cd}, \mathrm{Cu}, \mathrm{Ni}, \mathrm{Pb}$ and $\mathrm{Hg}$ in feces) and $\mathrm{Ca}$ in plasma ( $\mathrm{mg} / \mathrm{dl})$. The lighter areas denote lower values of the antioxidants, while darker areas denote higher values (some contours are labeled with the corresponding values). The GLMM models are shown in Table 2. 


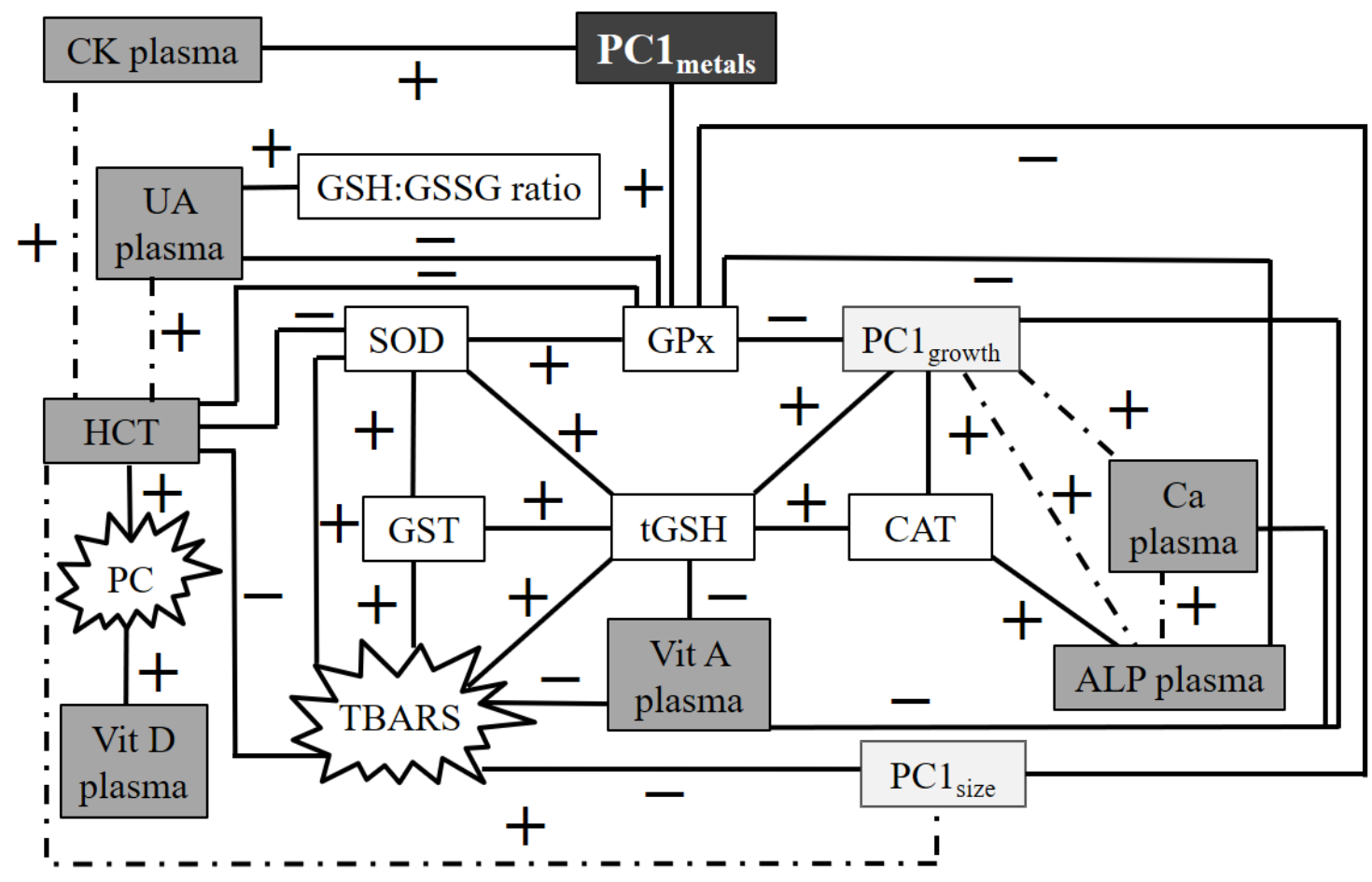

Figure 2. Relationships between $\mathrm{PC} 1_{\text {metals }}$ (first principal component of $\mathrm{As}, \mathrm{Cd}, \mathrm{Cu}, \mathrm{Ni}, \mathrm{Pb}$ and $\mathrm{Hg}$ in feces), oxidative status and damage, $\mathrm{Ca}$ and vitamins in plasma, $\mathrm{PC} 1_{\text {size }}$ (first principal component of wing, tarsus and head length and body mass) and $\mathrm{PC} 1_{\text {growth }}$ (first principal component of wing, mass, tarsus and head growth rate) in great tit nestlings. The directions of the relationships (Pearson and Spearman's correlations, Table S1) are shown with positive and negative signs. Solid lines mark relationships between variables from the present study, whereas dashed lines mark significant relationships observed in a previous publication from the same experiment (Espín et al., 2016a). Grayscale shades were intended to describe functional groups for different parameters. 
(a) Pollution effects
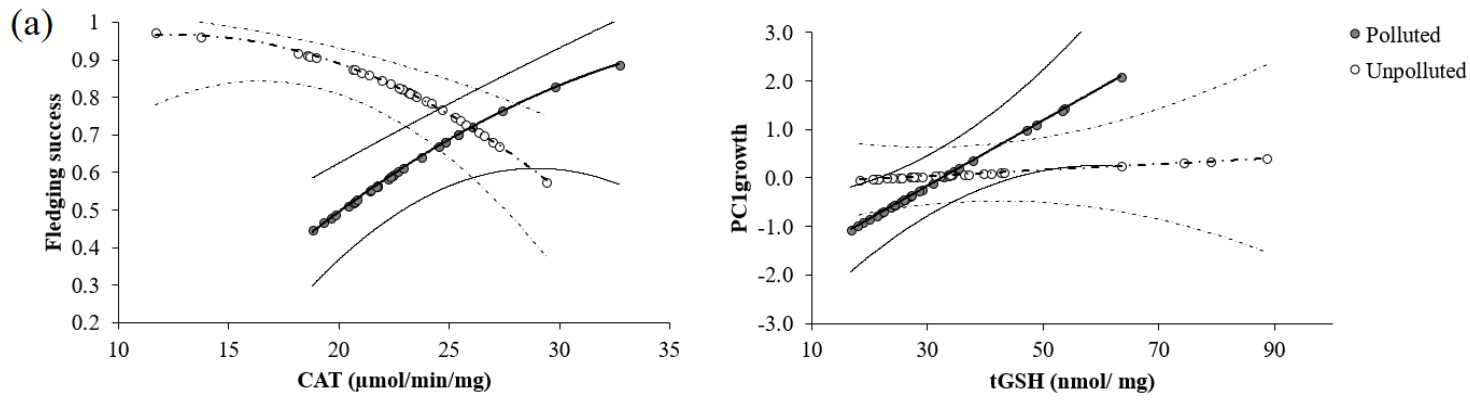

(b) Ca-treatment effects
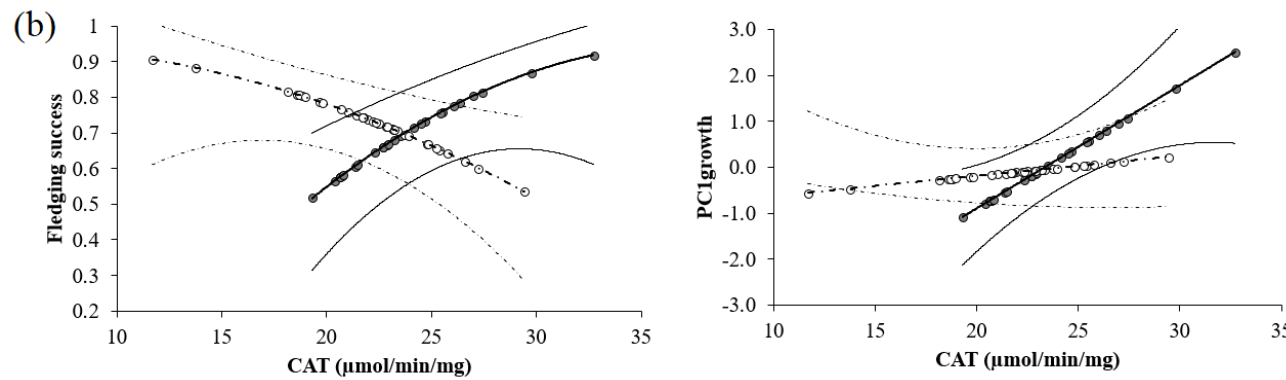

- Ca-supplemented $\circ$ Control
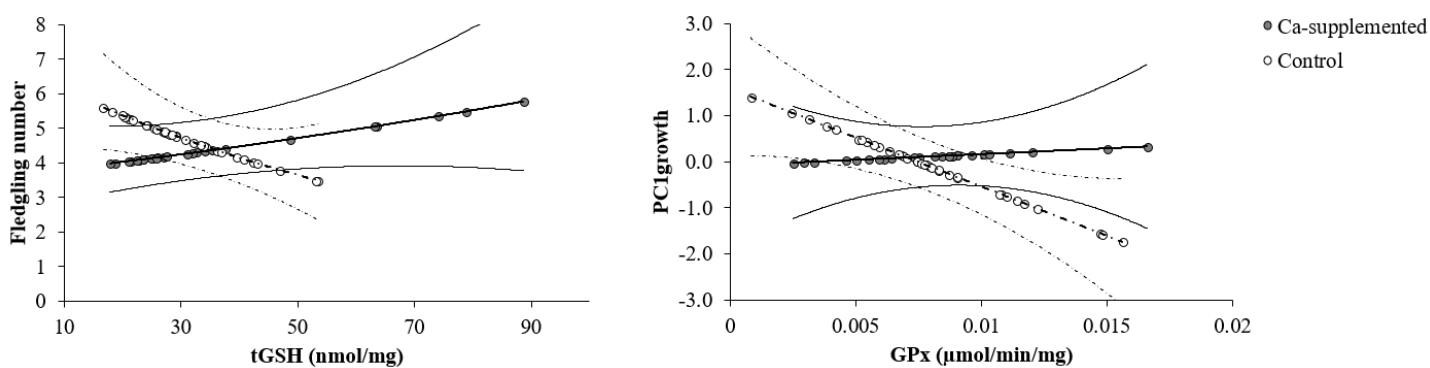

Figure 3. (a) The variation of fledging success (probability of a hatchling to fledge) relative to CAT activity $\left(\mathrm{F}_{\mathrm{ndf}, \mathrm{ddf}}=9.32_{1,58}, \mathrm{p}=0.0034, \mathrm{n}=62\right)$ and nestling growth rate ( $\mathrm{PC} 1_{\text {growth }}$, first principal component of wing, mass, tarsus and head growth) relative to tGSH levels in red cells of great tit nestlings $\left(\mathrm{F}_{\text {ndf,ddf }}=4.24_{1,58}, \mathrm{p}=0.044, \mathrm{n}=62\right)$ according to zone, and $(\mathrm{b})$ The variation of fledging success relative to CAT activity $\left(\mathrm{F}_{\mathrm{ndf}, \mathrm{ddf}}=6.08_{1,51.68}, \mathrm{p}=0.017, \mathrm{n}=62\right)$, nestling growth rate relative to CAT activity $\left(\mathrm{F}_{\text {ndf,ddf }}=3.14_{1,58}, \mathrm{p}=0.082, \mathrm{n}=62\right)$, number of fledglings relative to tGSH levels $\left(\mathrm{F}_{\text {ndf,ddf }}=\right.$ $\left.4.96_{1,57.99}, \mathrm{p}=0.030, \mathrm{n}=62\right)$ and nestling growth rate relative to GPx activity $\left(\mathrm{F}_{\text {ndf,ddf }}=3.80_{1,58}, \mathrm{p}=0.056\right.$, $\mathrm{n}=62)$ in red cells of great tit nestlings according to treatment. The data points $( \pm 95 \% \mathrm{CIs})$ are predicted values from the GLMM models. 


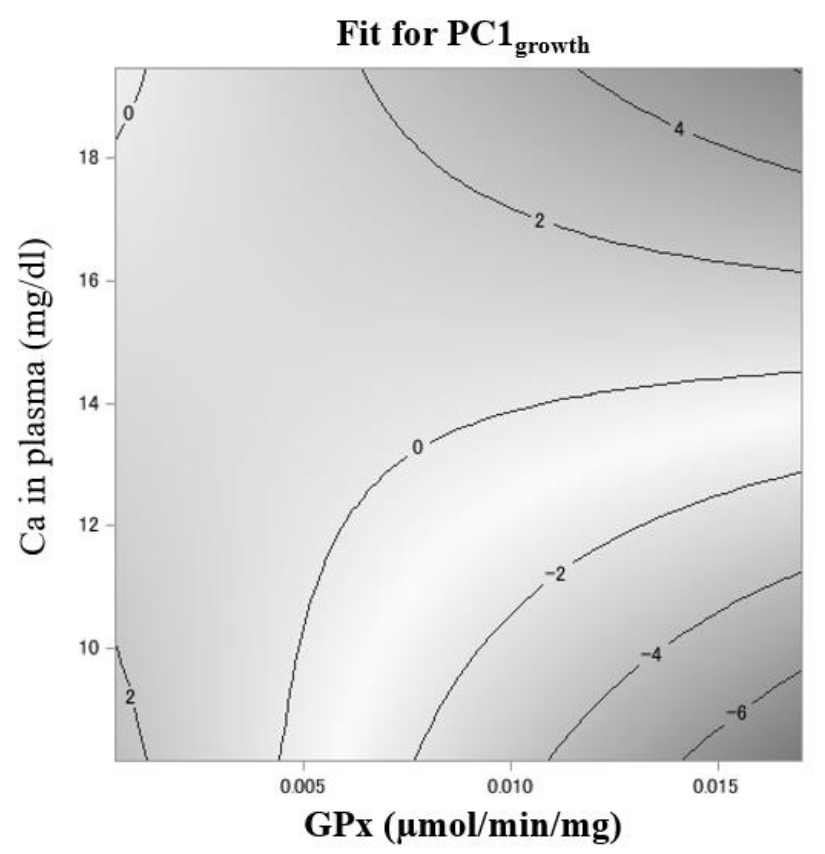

Figure 4. Contour plot for $\mathrm{PC} 1_{\text {growth }}$ (first principal component of wing, mass, tarsus and head growth rate) in great tit nestlings displaying the interaction between GPx activity and Ca in plasma (mg/dl) $\left(F_{n d f, d d f}=9.28_{1,58}, p=0.0035, n=62\right)$. Contours are labeled with the corresponding values. 